\section{(c)} (6)

\section{OPEN ACCESS}

- Additional material is published online only. To view please visit the journal online (http://dx.doi.org/10.1136/ thoraxjnl-2012-202646)

${ }^{1}$ School of Nursing and Midwifery, University of Newcastle, Newcastle, New South Wales, Australia ${ }^{2}$ School of Medicine and Public Health, University of Newcastle, Newcastle, New South Wales, Australia ${ }^{3}$ Department of Respiratory and Sleep Medicine, Hunter Medical Research Institute, John Hunter Hospital, New Lambton, New South Wales, Australia

${ }^{4}$ School of Biomedical Science, University of Newcastle, Newcastle, New South Wales, Australia

${ }^{5}$ Woolcock Institute of Medical Research, Sydney, New South Wales, Australia

\section{Correspondence to} Peter G Gibson,

Department of Respiratory and Sleep Medicine, Hunter Medical Research Institute, John Hunter Hospital, Locked Bag \#1000, New Lambton, NSW 2305, Australia; peter.gibson@hnehealth.nsw. gov.au

Received 27 August 2012 Revised 7 February 2013 Accepted 11 February 2013 Published Online First 16 March 2013

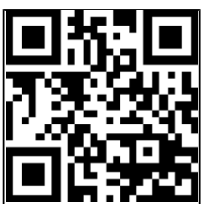

Open Access Scan to access $\mathrm{m}$ free content

\section{Linked}

- http://dx.doi.org/10.1136/ thoraxjnl-2012-202772

To cite: McDonald VM, Higgins I, Wood LG, et al. Thorax 2013;68:691-694.

\title{
Multidimensional assessment and tailored interventions for COPD: respiratory utopia or common sense?
}

\author{
Vanessa M McDonald, ${ }^{1,2,3}$ Isabel Higgins, ${ }^{1}$ Lisa G Wood, ${ }^{3,4}$ Peter G Gibson ${ }^{2,4,5}$
}

\begin{abstract}
Introduction The rising disease burden from chronic obstructive pulmonary disease (COPD) requires new approaches.
\end{abstract}

Method We suggest an approach based around three elements: inflammometry and multidimensional assessment to identify therapeutic targets and case management to design and implement an individualised treatment programme based on these assessments.

Discussion This tailored approach to treatment would maximise efficacy, limit cost and permit a better riskbenefit ratio of treatment. The advantages include the ability to add up the benefits of individual therapies leading to a cumulative therapeutic benefit that is greater than each individual therapy alone. We can now design a multifaceted inflammometry intervention for airway diseases based on targeting eosinophilic inflammation, non-eosinophilic pathways and systemic inflammation. COPD is a complex and challenging disease. The use of inflammometry and multidimensional assessment is necessary to identify relevant treatment targets and maximise the scope of therapy while limiting unnecessary use of drugs. An individualised programme of management can be designed and coordinated by using a case manager. This new approach may provide tangible benefits to people with COPD.

Chronic obstructive pulmonary disease (COPD) is a high impact disease, ${ }^{1}$ with a global trajectory that predicts an alarming increase in illness burden. ${ }^{2}$ Current approaches are unlikely to be sufficient to address this problem since they are largely based around disease management concepts that have been available for several years, at a time when the global COPD burden is escalating. New approaches are required and we suggest an approach that is based around three elements: the use of inflammometry and multidimensional assessment to identify therapeutic targets, and case management to design and implement an individualised treatment programme based on these assessments. ${ }^{3}$ Some see this as self-evident (common sense), whereas others see it as idealistic (respiratory utopia). We maintain it is both of these things, and more, since it offers a pragmatic and achievable approach to a complex condition, with the prospect of major health gains.

At the core of this approach is recognition of the heterogeneity in COPD. There is now considerable editorial space devoted to this subject. ${ }^{3-6}$ But do we actually apply this knowledge to the management of COPD?
Improvement in health status and avoidance of exacerbations are the key goals of management ${ }^{7}$ and it is now time to consider the heterogeneity of this disease in terms of treatment approaches. The current method is to apply a blanket approach to pharmaco-therapy that is informed by disease severity. The recently revised Global Initiative for Chronic Obstructive Lung Disease (GOLD) strategy suggests a graded approach to managing COPD, which involves short-acting bronchodilators and active reduction of risk factors (smoking cessation and vaccinations) across all COPD severity classifications. ${ }^{7}$ Pharmacotherapies including inhaled corticosteroids, long acting $\beta$ agonists (LABAs), long-acting antimuscarinics (LAMAs), theophylline and phosphodiesterase-4 inhibitors (PDE4) are recommended as severity, exacerbation frequency and symptoms increase. ${ }^{7}$ Newer therapeutic choices that target the inflammatory processes in COPD show great promise and their evidence base is increasing. These agents include macrolides as antibiotic/immunomodulatory agents ${ }^{8-10}$ and 3-hydroxy-3-methyl coenzyme A reductase inhibitors (statins) for systemic inflammation. ${ }^{11}$ However, because of the heterogeneity of COPD, the positioning of these agents in COPD pharmacotherapy is unclear. The currently recommended antiinflammatory treatment (inhaled corticosteroid) does not improve systemic inflammation, ${ }^{12}$ may worsen neutrophilic airway inflammation ${ }^{13}$ and when applied generally in COPD has a worrying pneumonia risk. ${ }^{14}$ Recent and ongoing studies (http://www.clinicaltrials.gov) of anti-inflammatories in COPD apply single agents generally to all patients with COPD. This approach fails to recognise the heterogeneity of inflammation in this disease and results in a therapeutic paradox, when key pathophysiological processes can escape therapeutic intervention.

This raises the question of whether a tailored approach to treatment would maximise efficacy, limit cost and permit a better risk-benefit ratio. With this approach the benefits of individual therapies are each added together to bring a cumulative therapeutic benefit. Such multifactorial intervention is common with non-pharmacological therapies, such as pulmonary rehabilitation and asthma selfmanagement education. Together with multidimensional assessment, it is also used successfully in other chronic diseases. The core elements of this approach are inflammometry (table 1), multidimensional assessment ${ }^{3}$ and case management. This 
Table 1 Inflammation-based algorithm

\begin{tabular}{|c|c|}
\hline Component & Management \\
\hline \multicolumn{2}{|l|}{ Airway inflammation } \\
\hline Eosinophilic (sputum eosinophil count \%>3) & ICS $500 \mu \mathrm{g}$ twice daily (beclomethasome equivalent) and prednisolone according to Siva ${ }^{23}$ \\
\hline Neutrophilic (sputum neutrophil count \%>61) & Azithromycin $250 \mathrm{mg}$ daily for 3 months \\
\hline Mucus hypersecretion & $\begin{array}{l}\text { Positive expiratory pressure device (Acapella) } \\
\text { Hypertonic saline } 6 \% \text { twice daily, nebulised }\end{array}$ \\
\hline Systemic inflammation (CRP >3 mg/litre) & Simvastatin $20 \mathrm{mg}$ daily for 3 months \\
\hline
\end{tabular}

article reports the concept, design and pilot testing of this approach.

\section{REAL WORLD EXAMPLE OF AIRWAY INFLAMMOMETRY CASE MANAGEMENT}

Older adults ( $>55$ years) with stable COPD (defined in online supplement) were recruited and allocated to usual care $(n=19)$ or multidimensional assessment and management $(n=17)$. The intervention consisted of individualised management based on the baseline multidimensional assessment. A personalised care plan was developed by the study physician and case manager. The clinicians and participants agreed on the tailored interventions for each of the identified problems. ${ }^{15}$ An inflammometry algorithm (table 1) was used to inform treatment decisions for airway inflammation, systemic inflammation and mucus hypersecretion. Other tailored interventions were standardised according to the best available evidence. ${ }^{3}$ The case manager coordinated the plan. The interventions were delivered over 3 months during individualised visits (see online supplement table 1). Pulmonary rehabilitation participation occurred concurrently.

The participant characteristics are presented in table 2 . The baseline multidimensional assessment identified a mean $(95 \%$ CI) of 10.5 (9.7 to 11.2 ) clinical management problems per participant. These problems clustered into four domains: airway related problems, comorbidity, risk factors and behavioural issues. $^{3}$

The primary outcome of health status improved significantly from baseline to 3-month follow-up in the intervention group. The mean (95\% CI) difference in St George's Respiratory
Questionnaire (SGRQ) for multidimensional assessment, airway inflammometry and individualised management (MDAIM) was 14 (20.7 to 8.5$)$ versus 3.5 ( -3.8 to 10.8$) ; p=0.0003$ for control (figure 1A). The mean $(95 \% \mathrm{CI})$ SGRQ score post intervention for MDAIM was 42.8 (35.3 to 50.4) versus 52 (45.1 to 58.9); $\mathrm{p}=0.06$ for control.

Clinically significant quality of life improvement (decreased SGRQ score $>4$ units at 3 months) was achieved in 14 (82.3\%) participants in the MDAIM group and 5 (31.2\%) in the control group $(p=0.003)$. The number needed to treat in order for one person to achieve a clinically significant change in SGRQ was 2.

In the MDAIM group health status continued to improve at 6-months follow-up (mean (95\% CI) decrease of 17.1 (7.1 to 27.1) units, $p=0.002)$ ) and was maintained at 12 months with a 13.5 (4.7 to 22.3$)$ unit decrease from baseline $(p=0.005)$. In the control group there was no statistically significant difference at either 6 months (4. $5(-1.2$ to 10.3$) ; \mathrm{p}=0.1)$ or 12 months (3.1 $(-3.5$ to 9.7$) ; \mathrm{p}=0.3)$.

Targeted inflammation-based management reduced eosinophilic and neutrophilic airway inflammation and systemic inflammation (figure 1B-D).

\section{DISCUSSION}

Airway and systemic inflammation in COPD is heterogeneous and since any one person can exhibit more than one inflammatory process (figure 2), any individual may require more than one therapeutic approach. For example, targeting neutrophilic inflammation alone will treat $57 \%$ of people with COPD (figure 2). ${ }^{16}$ Targeting eosinophilic inflammation will treat a further $34 \%$ and

Table 2 Baseline participant characteristics

\begin{tabular}{|c|c|c|}
\hline & Intervention & Control \\
\hline $\mathrm{N}$ & 17 & 19 \\
\hline Gender, M|F & $5 \mid 12$ & $13 \mid 6$ \\
\hline Age (years), mean $(95 \% \mathrm{Cl})$ & 70.6 (65.8 to 75.4$)$ & 71.1 (67.1 to 75.2$)$ \\
\hline Post-bronchodilator FEV1\% predicted, mean $(95 \% \mathrm{Cl})$ & 55 (43.5 to 67.2$)$ & $48(40.2$ to 55.3$)$ \\
\hline Post-bronchodilator FVC \% predicted, mean $(95 \% \mathrm{Cl})$ & 71 (63.1 to 79.2$)$ & 67 (59.3 to 73.6$)$ \\
\hline FER, mean $(95 \% \mathrm{Cl})$ & 0.59 (50.8 to 67.2$)$ & 0.51 (50.8 to 67.2$)$ \\
\hline SGRQ (units), mean $(95 \% \mathrm{Cl})$ & 57 (51.5 to 63.4) & 50 (44.0 to 55.5$)$ \\
\hline Smoking status, never|ex|current & $0|15| 2$ & $0|15| 4$ \\
\hline Charlson comorbidity index, mean $(95 \% \mathrm{Cl})$ & $4(3.3$ to 4.7$)$ & 4.1 (3.7 to 4.5$)$ \\
\hline BMI $\left(\mathrm{kg} / \mathrm{m}^{2}\right)$, mean $(95 \% \mathrm{Cl})$ & 27.8 (24.1 to 31.5$)$ & 28.4 (24.6 to 32.4$)$ \\
\hline CRP (mg/litre), median (IQR) & $5.3(2.5-9.5)$ & $6(2-9)$ \\
\hline Sputum neutrophils $(\%)$, mean $(95 \% \mathrm{Cl})$ & 59 (43.3 to 74.7$)$ & 59 (46.5 to 71.9$)$ \\
\hline Sputum eosinophils (\%), median (IQR) & $2.25(1-7)$ & $1.75(0.5-2.65)$ \\
\hline
\end{tabular}


A Difference in SGRQ at 3 months

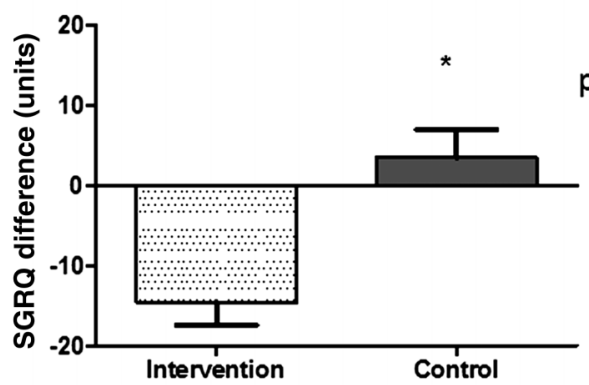

C Neutrophil (\%) in antibiotic-treated group

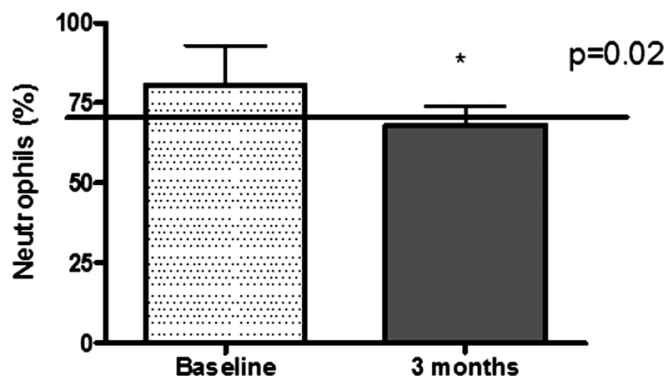

B Eosinophil (\%) in ocs-treated group

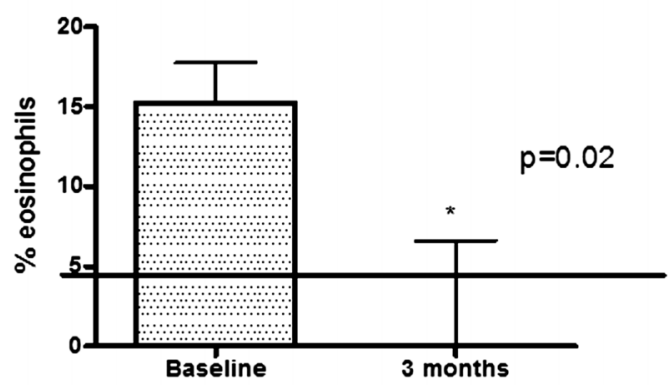

D CRP in statin-treated group

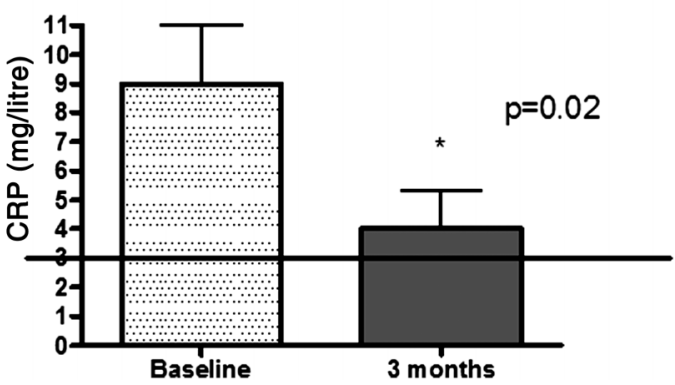

Figure 1 Biomarkers of inflammation in the group receiving treatment tailored to inflammation using the inflammation treatment algorithm. (A) Health status measured by St George's Respiratory Questionnaire (SGRQ) improved significantly (lower score) in the intervention group and worsened in the control group, as measured at 3 months. (B) In the group within multidimensional assessment, airway inflammometry and individualised management (MDAIM) that received oral corticosteroids (OCS) sputum eosinophils (\%) had normalised post intervention. The solid line represents the upper limit of normal for sputum eosinophils. (C) In the group within MDAIM that received antibiotics as anti-inflammatory agents sputum neutrophils (\%) had normalised post intervention. The solid line represents the upper limit of normal for sputum neutrophils. (D) In the group within MDAIM that received statins for systemic inflammation there was a statically significant reduction in serum high-sensitivity C-reactive protein (hs-CRP). The solid line represents the upper limit of normal of hs-CRP.

targeting systemic inflammation will manage this problem in 59\% of the COPD group. Drug therapy is increasingly pathway specific, and to target all of these different pathways in all people with COPD would require three drugs, that is, macrolide, statin and corticosteroid. A less costly and potentially safer approach is to use individual assessment and multicomponent therapy. We have

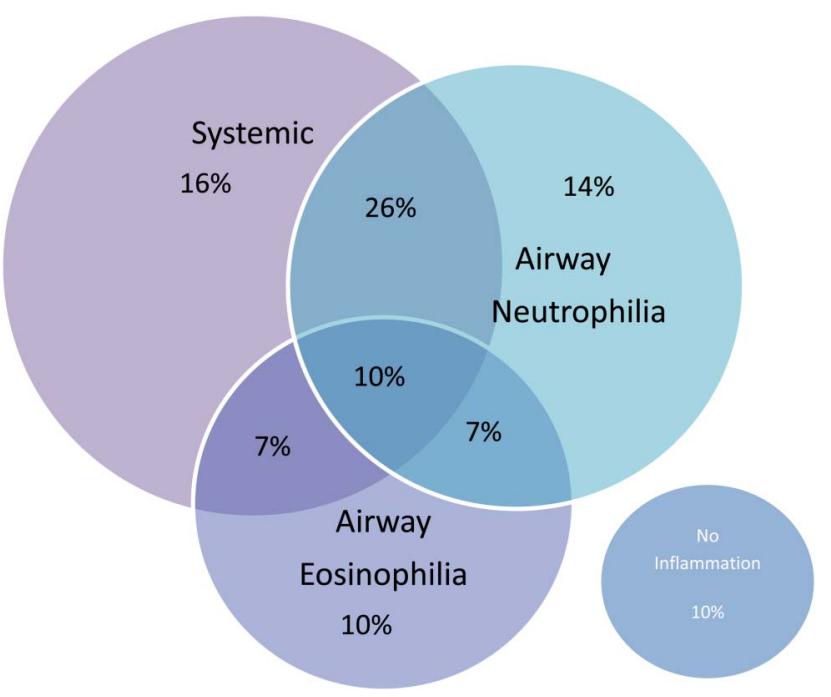

Figure 2 Venn diagram showing the prevalence of different inflammatory processes in chronic obstructive pulmonary disease. This figure is only reproduced in colour in the online version. developed a multifaceted approach that is likely to be highly effective and may be safer. ${ }^{3} 17$ The additive effects of targeted antiinflammatory treatment to eosinophilic, neutrophilic and systemic inflammation should show at least cumulative benefits, and result in a greater proportion of the COPD population receiving effective anti-inflammatory therapy. We recognise that antiinflammatory treatment in COPD needs to balance the nature of inflammation, treatment efficacy and the potential for adverse effects. For example, the broad application of macrolides is effective ${ }^{8}$ but there is a concern about side effects and microbial resistance. Consequently, an individually targeted approach may be a better way to maximise efficacy and minimise side effects.

\section{Inflammometry}

Current evidence can now be used to design a multifaceted inflammometry intervention for airway diseases. High-quality evidence reports the superior effects of targeting airway eosinophilic inflammation in asthma and COPD, ${ }^{9} 18-23$ with a $50 \%$ reduction in exacerbations. Non-eosinophilic inflammatory pathways are addressed using macrolide antibiotics as immunomodulatory agents and studies demonstrate reductions in exacerbations, improved lung function and improved health status. ${ }^{8} 9$ Systemic inflammation represents a further pathway that could be identified by inflammometry and targeted by statins. In COPD an increasing number of observational studies report the positive effects of statins, including a reduced number of COPD exacerbations, ${ }^{24-26}$ reduced lung function decline, ${ }^{25}$ improved exercise capacity ${ }^{27}$ and reduced mortality. ${ }^{11} 26 \quad 28 \quad 29$ These 
published studies have targeted specific inflammatory processes in isolation, and while they show efficacy, to date there are no other published studies other than these pilot data that treat the overlapping features of the inflammatory processes present in individuals with COPD. Our composite inflammatory algorithm is described (table 1).

\section{Case management}

The needs of patients with COPD are complex and multidimensional, and as clinicians, our responses must also be multidimensional and integrated to meet these needs. Case management is an approach that offers a solution to these healthcare delivery issues in COPD. This approach can be used to complement individualised and phenotype-based treatments in this complex population.

This approach brings together multidimensional assessment, inflammometry and case management. It need not be restricted to COPD, but could usefully be applied to other chronic airway diseases, such as severe asthma and bronchiectasis. We have targeted problems that clustered into four domains: airway-related problems, comorbidity, risk factors and behavioural issues. There are additional issues that could be addressed and require further consideration, such as end of life care and whether disease severity using either GOLD stage or BODE (body mass index/airflow obstruction/dyspnea/exercise capacity) index has an impact on problem assessment and management.

When looking at the prospects and challenges of COPD management in the future, this form of respiratory utopia makes a certain amount of commonsense!

Acknowledgements The pilot study was funded by the Hunter Medical Research Institute and the John Hunter Hospital Charitable Trust Grants. VMMcD was the recipient of an NHMRC Centre for Respiratory and Sleep Medicine PhD scholarship, and a Cooperative Research Centre for Asthma PhD scholarship. PGG is an NHMRC Practitioner Fellowship recipient. The authors would like to thank and acknowledge Heather Powell for her statistical advice. Additionally we would like to thank and acknowledge Amber Smith for the dietary intervention, Kelly Steel, Rebecca Oldham and Joanne Smart for data collection, the CARD laboratory team for sample processing and the participants for taking part.

Contributors VMMCD: project conception, study design, data collection, data analysis, data interpretation, writing and revisions of the manuscript, study design and revisions of the manuscript. IH: study design and review of manuscript. LGW: study design and review of manuscript. PGG: project conception, study design, data interpretation, and writing/revision of manuscript.

Competing interests Dr Vanessa McDonald has been reimbursed for participation in educational meetings from AstraZeneca, Boehringer Ingelheim GlaxoSmithKline and Novartis. She has participated in studies funded by GlaxoSmithKline. Professor Isabel Higgins has no competing interests to declare. Dr Lisa G Wood has no competing interests to declare. Professor Peter Gibson holds an NHMRC Practitioner Fellowship. He has been reimbursed for participation in symposia funded by AstraZeneca, Boehringer Ingelheim, GlaxoSmithKline and Novartis. He has participated in studies funded by Pharmaxis and GlaxoSmithKline.

Ethics approval Hunter New England Human Research and Ethics Committee and University of Newcastle.

Provenance and peer review Not commissioned; internally peer reviewed.

Open Access This is an Open Access article distributed in accordance with the Creative Commons Attribution Non Commercial (CC BY-NC 3.0) license, which permits others to distribute, remix, adapt, build upon this work non-commercially, and license their derivative works on different terms, provided the original work is properly cited and the use is non-commercial. See: http://creativecommons.org/licenses/by-nc/3.0/

\section{REFERENCES}

1 Buist SA, McBurnie MA, Vollmer WM, et al. International variation in the prevalence of COPD (the BOLD Study): a population-based prevalence study. Lancet $2007 \cdot 370: 741-50$
2 Mathers CVT, Stephenson C. The Burden of Disease and Injury in Australia. AIWH Cat. No. PHE-17. Canberra: Australian Institute of Health and Welfare. 1999.

3 Gibson PG, McDonald VM, Marks GB. Asthma in the older adult. Lancet 2010:374:803-13.

4 Antonelli Incalzi R, Pedone C, Pahor M. Multidimensional assessment and treatment of the elderly with COPD. Eur Respir Mon 2009:35-55.

5 Beasley $\mathrm{R}$, Weatherall M, Travers J, et al. Time to define the disorders of the syndrome of COPD. Lancet 2009;29:670-2.

6 Guerra S. Asthma and chronic obstructive pulmonary disease. Curr Opin Allergy Clin Immunol 2009:9:409-16.

7 Global Initiative for Chronic Obstructive Lung Disease (GOLD). Global Strategy for the Diagnosis, Management and Prevention of Chronic Obstructive Pulmonary Disease. Vancouver: GOLD. 2011

8 Albert RK, Connett J, Bailey WC, et al. Azithromycin for prevention of exacerbations of COPD. N Engl J Med 2011;365:689-98.

9 Simpson JL, Powell H, Boyle MJ, et al. Clarithromycin targets neutrophilic airway inflammation in refractory asthma. Am J Respir Crit Care Med 2008;177: 148-55.

10 Rubin BK, Henke MO. Immunomodulatory activity and effectiveness of macrolides in chronic airway disease. Chest 2004;125(2 Suppl):70S-8S.

11 Lee T-M, Lin M-S, Chang N-C. Usefulness of C-reactive protein and interleukin-6 as predictors of outcomes in patients with chronic obstructive pulmonary disease receiving pravastatin. Am J Cardiol 2008:101:530-5.

12 Sin DD, Man SF, Marciniuk DD, et al. The effects of fluticasone with or without salmeterol on systemic biomarkers of inflammation in chronic obstructive pulmonary disease. Am J Respir Crit Care Med 2008;177:1207-14.

13 Cowan DC, Cowan J0, Palmay R, et al. Effects of steroid therapy on inflammatory cell subtypes in asthma. Thorax 2010;65:384-90.

14 Crim C, Calverley PM, Anderson JA, et al. Pneumonia risk in COPD patients receiving inhaled corticosteroids alone or in combination: TORCH study results. Eur Respir J 2009;34:641-7.

15 McDonald VM, Higgins I, Simpson JL, et al. The importance of clinical management problems in older people with COPD and asthma; do patients and physicians agree? Prim Care Respir J 2011:20:389-95.

16 McDonald VM, Simpson JL, Higgins I, et al. Multidimensional assessment of older people with asthma \& COPD: clinical management and health status. Age Ageing 2011;40:42-9.

17 McDonald VM, Higgins I, Gibson PG. Managing older patients with coexistent asthma and chronic obstructive pulmonary disease: diagnostic and therapeutic challenges. Drugs Aging 2012;11:11.

18 Powell H, Murphy VE, Taylor DR, et al. Management of asthma in pregnancy guided by measurement of fraction of exhaled nitric oxide: a double-blind, randomised controlled trial. Lancet 2011:378:983-90.

19 Nair P, Pizzichini MM, Kjarsgaard M, et al. Mepolizumab for prednisone-dependent asthma with sputum eosinophilia. N Engl J Med 2009;360:985-93.

20 Green RH, Brightling CE, McKenna S, et al. Asthma exacerbations and sputum eosinophil counts: a randomised controlled trial. Lancet 2002:30:1715-21.

21 Jayaram L, Pizzichini MM, Cook RJ, et al. Determining asthma treatment by monitoring sputum cell counts: effect on exacerbations. Eur Respir J 2006:27:483-94.

22 Siva R, Green RH, Brightling CE, et al. Eosinophilic airway inflammation and exacerbations of COPD: a randomised controlled trial. Eur Respir 2007;29:906-13.

23 Petsky HL, Kynaston JA, Turner $\mathrm{C}$, et al. Tailored interventions based on sputum eosinophils versus clinical symptoms for asthma in children and adults. Cochrane Database Syst Rev 2007: (2): CD005603.

24 Blamoun Al, Batty GN, DeBari VA, et al. Statins may reduce episodes of exacerbation and the requirement for intubation in patients with COPD: evidence from a retrospective cohort study. Int J Clin Pract 2008:62:1373-8.

25 Keddissi J, Younis WG, Chbeir EA, et al. The use of statins and lung function in current and former smokers. Chest 2007;132:1764-71.

26 Mancini GB, Etminan M, Zhang $B$, et al. Reduction of morbidity and mortality by statins, angiotensin-converting enzyme inhibitors, and angiotensin receptor blockers in patients with chronic obstructive pulmonary disease. J Am Coll Cardiol 2006:47:2554-60

27 Lee T-M, Chen C-C, Shen H-N, et al. Effects of pravastatin on functional capacity in patients with chronic obstructive pulmonary disease and pulmonary hypertension. Clin Sci 2009;116:497-505.

28 Frost FJ, Petersen $\mathrm{H}$, Tollestrup $\mathrm{K}$, et al. Influenza and COPD mortality protection as pleiotropic, dose-dependent effects of statins. Chest 2007;131: 1006-12.

29 Ishida W, Kajiwara T, Taneichi H, et al. Decrease in mortality rate of chronic obstructive pulmonary disease (COPD) with statin use: a population-based analysis in Japan. Tohoku J Exp Med 2007:212:265-73. 